\title{
Variable flow and optimization of chiller loading effect on energy saving for screw vapor compression-single effect absorption hybrid chiller plant in hospital mechanical room - case study: Tehran heart hospital
}

\author{
Ronald Boghosian ${ }^{1}$, Mostafa Mafi $^{2, *}$, Mohammad Hassan Panjeshahi ${ }^{3}$, and Abtin Ataei ${ }^{4}$ \\ ${ }^{1}$ Department of Energy engineering, Science and Research Branch, Islamic Azad University, Tehran, Iran \\ 2 Department of Mechanical engineering, Imam Khomeini International University, Qazvin, Iran \\ ${ }^{3}$ Department of Chemical engineering, University of Tehran, Tehran, Iran \\ ${ }^{4}$ School of Engineering, University of Dayton, Dayton, USA
}

Received: 1 September 2020 / Accepted: 20 January 2021

\begin{abstract}
Chiller plants are the most energy consuming system during summer season in residential, commercial and hospital buildings. The highly variable cooling demand of the buildings connected to a hybrid chiller plant included absorption and vapor compression chillers to achieve higher energy efficiencies is one of the important issues. Cooling load sharing strategies and apply the variable water flow system in chiller plant have a significant impact on energy consumption and consequently with more productivity and environmentally protected. This paper examines the behavior and pattern of energy consumption in a hybrid chiller plant that includes a combination of two air-cooled screw vapor compression and three single effect absorption chillers. In order to properly understand the pattern of energy consumption, an existing mechanical room in a hospital in Tehran has been studied for five months, and its energy consumption has been compared with the optimized model. The results indicate that the sequence of the chiller function and the way in which they are placed in the circuit during a partial load, is in highest importance in view point of energy saving also by Applying of variable water flow system for optimized chiller loading the more energy saving is achieved for hybrid absorption and vapor compression chiller plant.
\end{abstract}

Keywords: Chiller plant / variable speed / energy consumption / hospital / sequence of operation

\section{Introduction}

Hospitals have a high energy consumption rate [1]. HVAC system accounts for $51.36 \%$ total energy consumed by most of hospital buildings [2]. Air-conditioning, boilers, and lighting systems are the main directions for energy efficiency in hospital buildings [3]. The results of study on 3 hospital in Australia show that the energy consumption by Heating and cooling together constitute $44-47 \%$, for hospital buildings [4]. In HVAC plants of medium-high cooling capacity, multiple chiller configurations is more frequently adopted than single chiller [5]. Alessandro Beghi reported that significant energy savings can be achieved by optimizing chiller operation [6].

\footnotetext{
* e-mail: m.mafi@eng.ikiu.ac.ir
}

Variable speed water circulation system is one of the methods that are used for energy optimization for chiller plants. Variable flow, primary-only systems reduced total annual plant energy use by $2-5 \%$ [7]. Luigi Schibuola presents a detailed assessment of the impact of the VSDs to HVAC components on public buildings [8]. In HVAC systems a fundamental contribution to energy saving can be obtained by the installation of devices with the capability to fit the motor speed to the actual exigencies of the building demand which for the most part of the year is significantly lower than the design peaks used for sizing the HVAC system application of VSDs to HVAC components in a public building [9]. In HVAC systems a fundamental contribution to energy saving can be obtained by the installation of devices with the capability to fit the motor speed to the actual exigencies of the building demand which for the most part of the year is significantly lower than the design peaks used for sizing the HVAC 
system [10] Hartman [11] also highlighted the all variable speed chiller plants which chiller, condenser pumps and cooling tower fans were driven by VSD to achieve the highest energy performance especially at partial load conditions.

Each area of the hospital has a specific humidity, temperature and pressure according to its usage (In accordance with domestic and international standards) $[12,13]$. As reported by the US DCD magazine [14], when equipping a hospital, the largest construction cost per unit area is related to hospital HVAC facilities and ventilation systems. With respect to a report by the AEO [15], the energy consumption of buildings in the United States in 2010 is $41 \%$ of primary energy consumption. According to the International Energy Agency (IEA) [16], 20-40\% of the final energy in developed countries is related to heating, cooling and air conditioning systems. In a report presented by Louise Perez Lombard et al. [17] heating, cooling, and air conditioning systems have the highest energy consumption of about $50 \%$ of the final energy of buildings, and they account for between one third and one fifth of the final energy in developed countries.

More than 40 percent of energy consumption in commercial and industrial buildings for cooling is related to energy consumption of chillers [18]. Of course, this amount of energy in the chillers is being optimized. For example; water-cooled chillers in the 1970s had a power consumption of $0.9 \mathrm{~kW} /$ ton, which after thirty years passed was reduced to $0.5 \mathrm{~kW} /$ ton [19]. According to a research by Sundar Raj et al. [20], optimizing the performance of chillers in multi-chiller operating systems for commercial building with a mean capacity of $40 \%$ results, $20 \%$ percent reduction in energy consumption of the plant and for chiller plants by one centrifugal chiller with the capacity of 1200 Ton.R and two absorption chiller with the capacity of 659 Ton.R for each one $40.3 \%$ energy saving was achieved by energy optimization methodology.

One of the energy modeling software used to model building shells, as well as the air conditioning and central mechanical room system, is eQuest software. With the modeling of a hotel in China with eQuest software, Jincheng xing et al. [21] calculated the difference in theoretical and practical power consumption by $15 \%$. Also, according to the measurements, the coefficient of performance in the Vapor compression chillers is less than 4 at part load. Neto Flavio et al. [22] stated that eQuest software is a valuable model for managing BEER proposals. Ming Tsun Kea et al. [23], in modeling the office building by eQuest software, they had reported that the mean bias error (MBE) and root mean square error (RMSE) for uncalibrated simulation results are $24.48 \%$ and in the calibrated model it was $0.37 \%$, compared to actual energy consumption. Sozer [24] modeled residential buildings in eQuest software and he examined the effects of building shell on energy consumption and concluded that optimizing building shell would improve $11.33 \%$ of building energy consumption. Kim et al. [25] studied the effect of the double low- E windows with a solar film with eQuest software on annual electric energy consumption and peak demand of the commercial building. As a result, internal and external solar film coatings reduced cooling loads by $2.2 \%$ and $27.5 \%$, respectively.

One of the challenges in designing a central mechanical room for buildings such as the hospital building is the type of chillers (Vapor compression or absorption). Due to the presence of a steam system for use in a launderette, disinfection area, etc., it is possible to use absorption chillers by having increased boiler capacity. Also due to the sensitive and variable temperature conditions in hospital spaces, the use of Vapor compression chillers due to its flexibility and less contamination in the hospital is also recommended. The purpose of this research is to determine the amount of energy consumption of electricity and natural gas for vapor compression and absorption chillers with regard to capacity changes, chiller loads sharing and applying the variable water flow for the hybrid chiller plant of the existing hospital building.

\section{Description of case study}

In order to realize the pattern of energy consumption for hospital mechanical rooms, an existing mechanical room for Heart hospital in Tehran has been studied for six months and its energy consumption has been compared with the software modeling.

The complex has an area of 18000 square meters on 8 floors, taking into account the ground floor, and also has 3 floors below ground level. The most important spaces of the hospital which require a HVAC and ventilation system, are in reception area, radiology and laboratory in the ground floor, operating rooms on the first floor, ICU, CCU in the first and third. The air-conditioner room (32 air-handling units) is located on the second floor and the $3,4,5,6$ floors are included hospital rooms. The 7th floor is for physicians' rooms and dormitories. The restaurant, the chapel, and the CTI Anjou are located in the minus one Floor, kitchen, CSR and laundry room on the minus two Floor, and the mechanical room, lab and parking are located in the minus three. The main equipment in the mechanical and airhandling room is presented in Table 1.

A combination of five absorption and vapor compression chillers is working to maintain the cooling load of the whole hospital spaces, three of them are a single-effect steam powered absorption chiller each one with a capacity of 525 tons and two air-cooled screw type Vapor compression chillers with remote air-cooled condensers, each of them with a nominal capacity of 500 tons and 350 of actual ton each chiller consists of 4 semi-hermetic screw compressor with 4 steps unloading controller that is operated with slide valve. Also, for the heating and absorption cooling system of the hospital, three boilers, each with a capacity of 22000 pounds per hour are considered, so that the steam is used to feed the absorption chiller generator for cooling. Also, the above steam is used for heat exchangers, domestic hot water generators and the heat exchangers that supply the hot water for air handling heating coils and fan coils. The schematic of the hybrid chiller plant it is shown in Figure 1.

For the transfer of cooling system fluid, seven continuous constant flow centrifugal pump units are considered. 
Table 1. Tehran heart hospital building physical attributes.

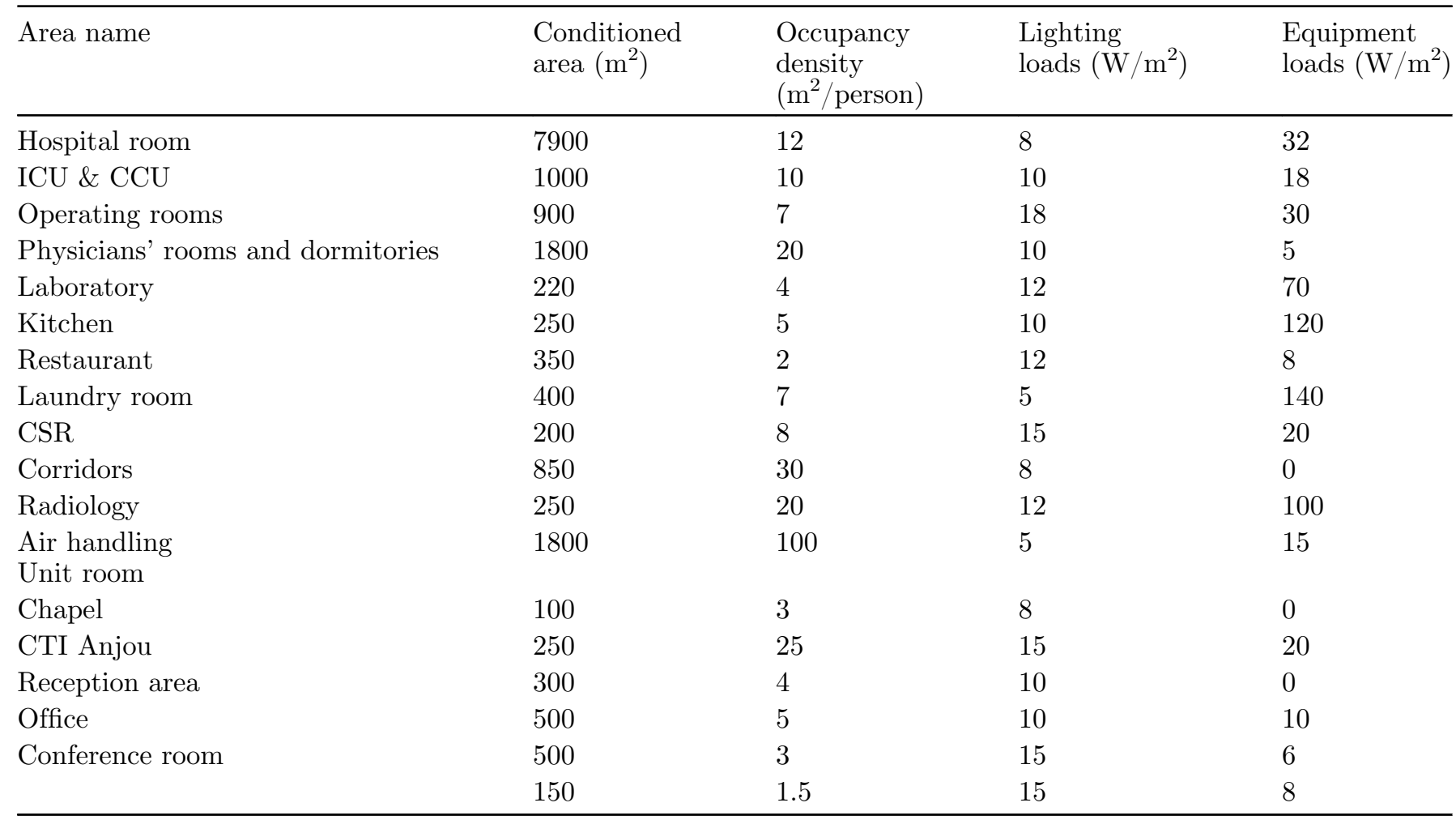

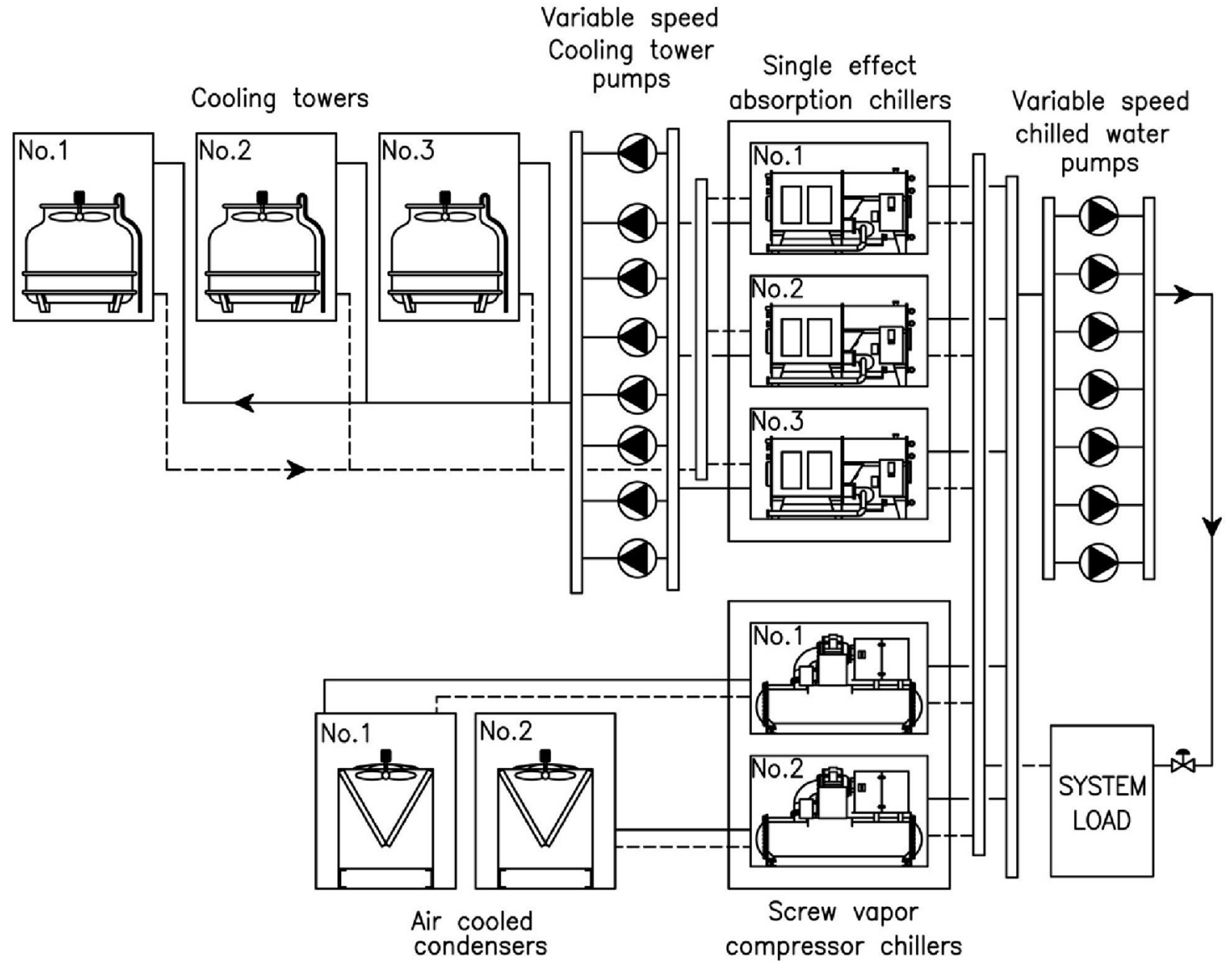

Fig. 1. Schematic diagram of Tehran hospital hybrid chiller plant (case-study). 
Table 2. Main equipment located in the mechanical of the Tehran heart hospital building.

\begin{tabular}{llll}
\hline Item & Equipment & Numbers of equipment & Actual capacity (each one) \\
\hline 1 & Single effect absorption chiller & 3 & 525 Ton \\
2 & Air cooled screw compressor chiller & 2 & 350 Ton \\
3 & Steam boiler & 3 & $22000 \mathrm{lb} / \mathrm{hr}$ \\
4 & Cooling tower (for absorption chillers) & 3 & $550 \mathrm{Ton}$ \\
\hline
\end{tabular}

Also Tehran Heart hospital building physical attributes are presented in Table 1 and the main equipment located in mechanical room are presented in Table 2 respectively.

\section{Data collection}

To study the pattern of energy consumption in the hybrid chiller plant To measure Tehran heart hospital mechanical room parameters including temperature of the outlet and input water of each chillers, temperature of entering and exiting water of cooling towers, the number of chillers in the circuit, the number of compressors in the circuit for screw vapor compression chillers and the amount of electricity current for each compressor, and the amount of electricity current for each evaporator and condenser pumps and the flow of chilled water and cooling water were measured. A field study for data collection has been conducted. All above mentioned parameters have been measured at a time interval of $2 \mathrm{~h}$ per day, a total of 4200 field data series has been collected for evaluating the performance of each vapor compression and absorption chiller over a period of five months among May-September.

\section{Energy modeling}

In order to study the effect of absorption and vapor compression chillers sequencing load share and variable evaporator flow together on energy consumption in the hybrid chiller plant, a computer model was prepared using eQuest software and the results were compared with the experimental data collected during field studies. The architecture of the building is modeled using the architectural drawings with the software. And then, according to the mechanical system, the equipment's consist of Vapor compression chillers, absorption chillers, boilers and operating evaporator and condenser pumps system, cooling towers and air cooled condensers of screw chillers have been modeled (Fig. 2).

\section{Scenarios}

In order to investigate the sequence of operation and time of partial load of chillers and the variable evaporator flow on energy consumption in the hybrid chiller plant with three single effect absorption and two screw vapor compressor chillers in heart hospital mechanical room, three scenarios are considered as follow:
- Scenario 1: measured practical data was analyzed in the actual operating conditions of chillers and also the behavior of them at different hours with regard to constant water flow, sequencing and capacity change are indicated.

- Scenario 2: the same system and their cooling load sharing strategies and chillers sequencing were modeled and optimized in eQuest software for reducing the energy consumption.

- Scenario 3: considering variable speed drive (VSD) for circulation pumps to evaluate the energy consumption in optimized cooling load sharing system.

Due to the fact that chiller compressors are screwed and semi-hermetic and each chiller has four compressors, changing the capacity of chillers during partial loads is as follows:

- On and off operation of chiller/compressor.

- Using a step control of the slide valve inside the compressors (4 steps of 100-75-50-25\%) (Fig. 2).

\section{Discussion}

In order to investigate the sequence of operation and time of a partial load of chillers on energy consumption, three scenarios are considered. In scenario 1, actual operating conditions of chiller plant with constant flow and pump speed are obtained. In scenario 2 , the sequence of operation and time of a partial load of chillers is optimized to minimizing energy consumption of the plant.

In scenario 3 variable flow water system considering variable speed drive (VSD) for circulation pumps with optimized chiller sequencing to evaluate the energy consumption.

\subsection{Scenario 1: actual operating conditions}

In this scenario, the cooling energy of the hospital produced by the mentioned chillers is calculated by examining the statistical, practical data in different months and the operating conditions of the mechanical room. Also, during this study, the proportion of absorption and Vapor compression chillers were calculated to provide the cooling load required for the hospital.

Power consumption of screw compressors with its output cooling capacity is not linear during partial loads [26]. The electric energy consumption of Vapor 


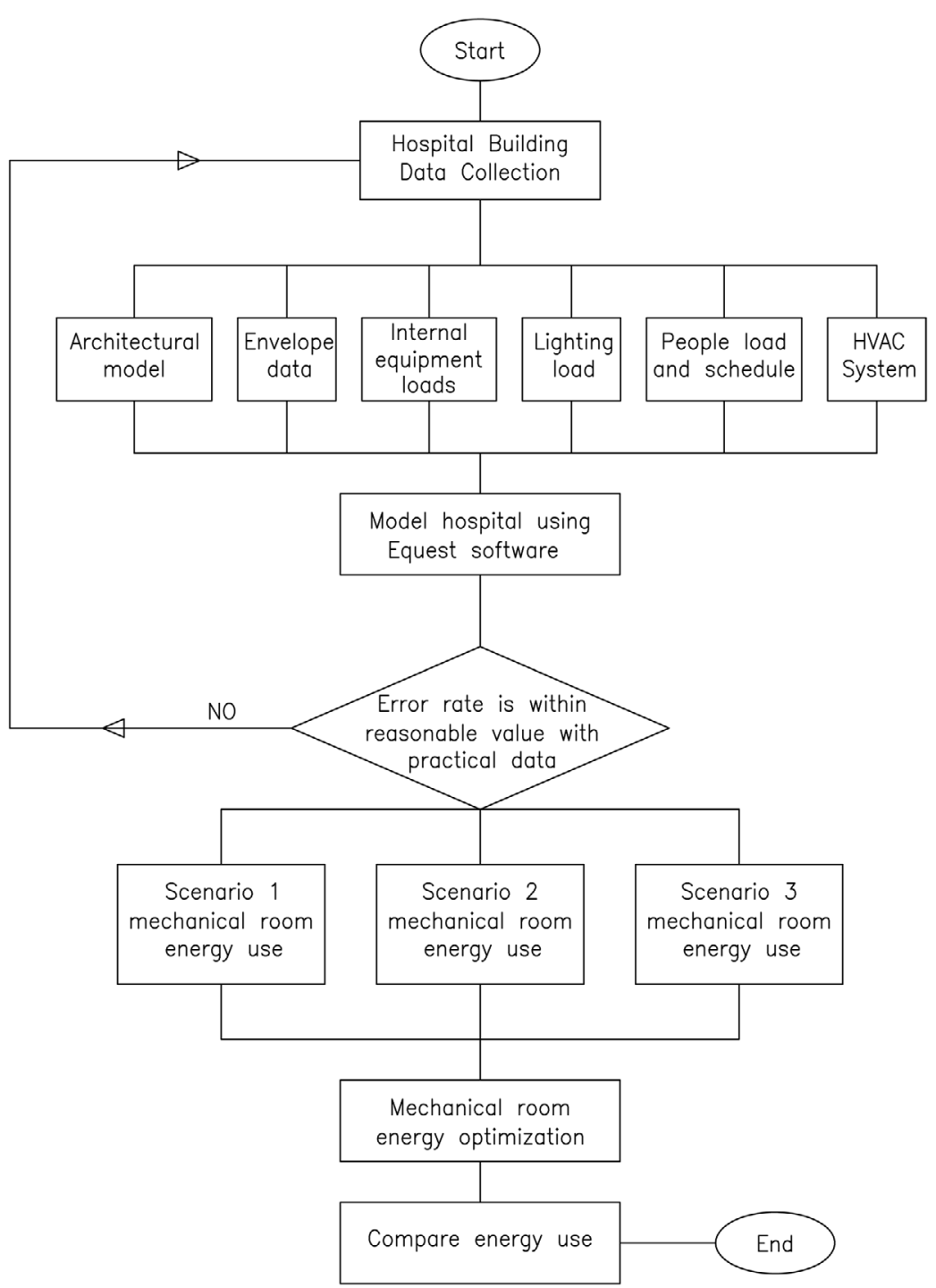

Fig. 2. Algorithm of modeling.

compression chillers can be calculated as follows:

$$
P=\sqrt{3} V I \cos \emptyset
$$

In that case, $\cos \emptyset$, the coefficient of power of the electric system, is intermittent and equal to 0.85 [27]. In order to estimate the cooling load due to changes in the load factor during the day and in different seasons, the data recorded in 2-h intervals have been used. Equation (2) is used to calculate the cooling capacity of each chiller.

$$
\mathrm{CL}=500 \dot{\mathrm{v}} \Delta \mathrm{T}
$$

where $\dot{\mathrm{v}}$ is the flow rate of each chiller in gallon per minute, and $\Delta \mathrm{T}$ is the difference in temperature between the evaporator's inlet and outlet each of chiller and in degrees Fahrenheit [28].
Regarding the use of steam to supply heat to the absorption chiller generator, it is necessary to estimate the amount of steam used and consequently to estimate the consumption of natural gas. It is not possible to directly estimate steam consumption through the capacity of steam boilers because of various uses of steam such as; a launderette, antiseptic, hot water generation, air conditioning coil heating, etc. Therefore, the amount of natural gas consumed in steam generation with required working pressure from the manufacturer of absorption chillers has been calculated. The amount of steam used for each absorption chiller is 10566 pounds per hour and at a pressure of 15 pounds per square inch. Regarding the gas thermal value and the efficiency of the boiler burner, the natural gas consumption for each absorption chillers, taking into account the thermal value of natural gas as $8600 \mathrm{kcal} / \mathrm{m}^{3}$, is equivalent to 0.73 cubic meters per hour per ton of refrigeration for absorption chiller. 

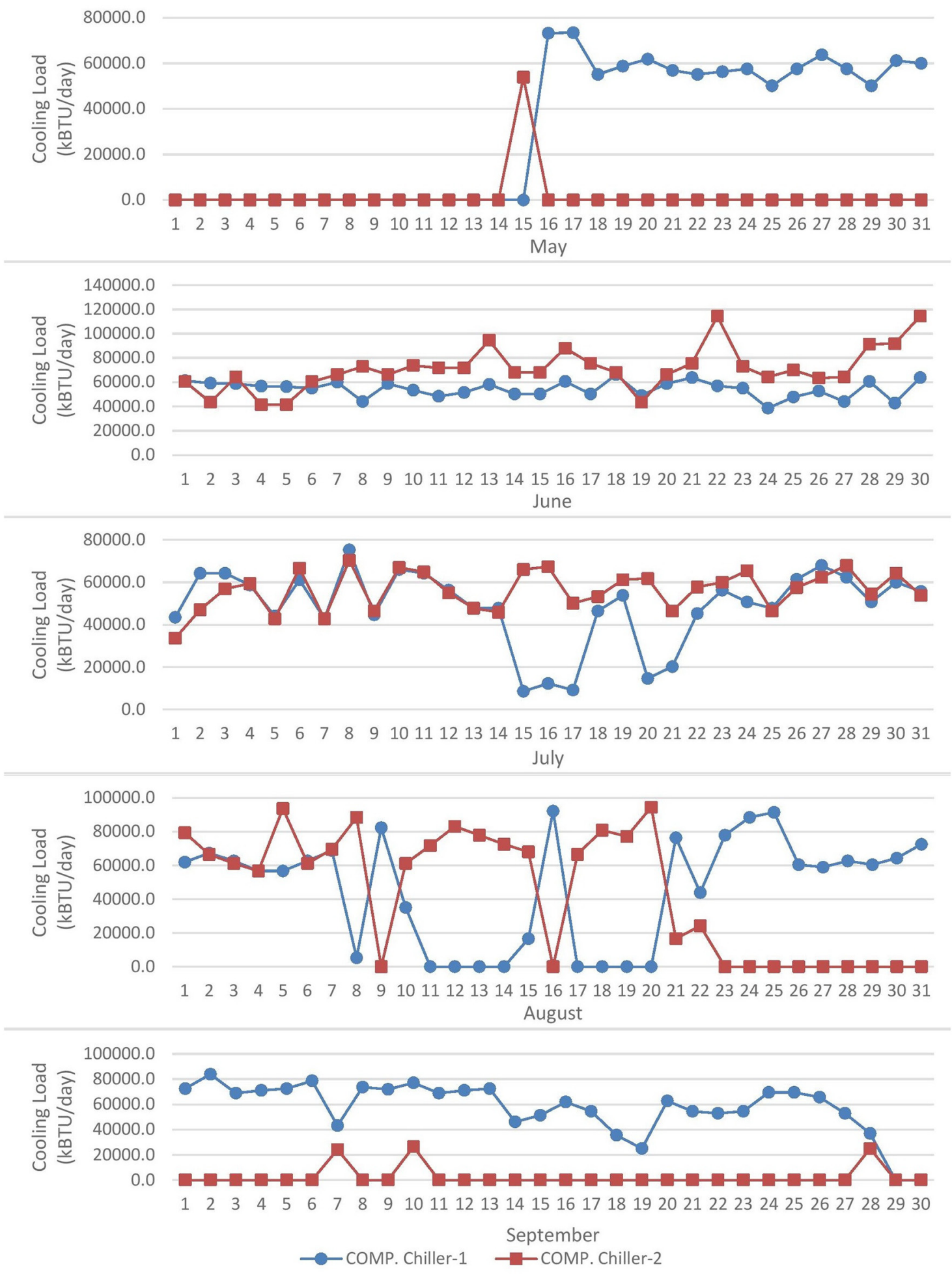

Fig. 3. Vapor compression chillers cooling load in May-September.

The pattern of operation in circuit and unloading of chillers and related produced cooling loads for months of May-September is presented in Figures 3-5.

Also, the amount of cooling load provided by vapor compression and absorption chillers on a monthly basis is shown in Figures 6 and 7 respectively.

\subsection{Scenario 2: (eQuest software modeling)}

By modeling the Tehran Heart hospital in the eQuest software, the behavior of the system is investigated and the optimal sequence of operation and time of a partial load in chiller plant can be obtained. 

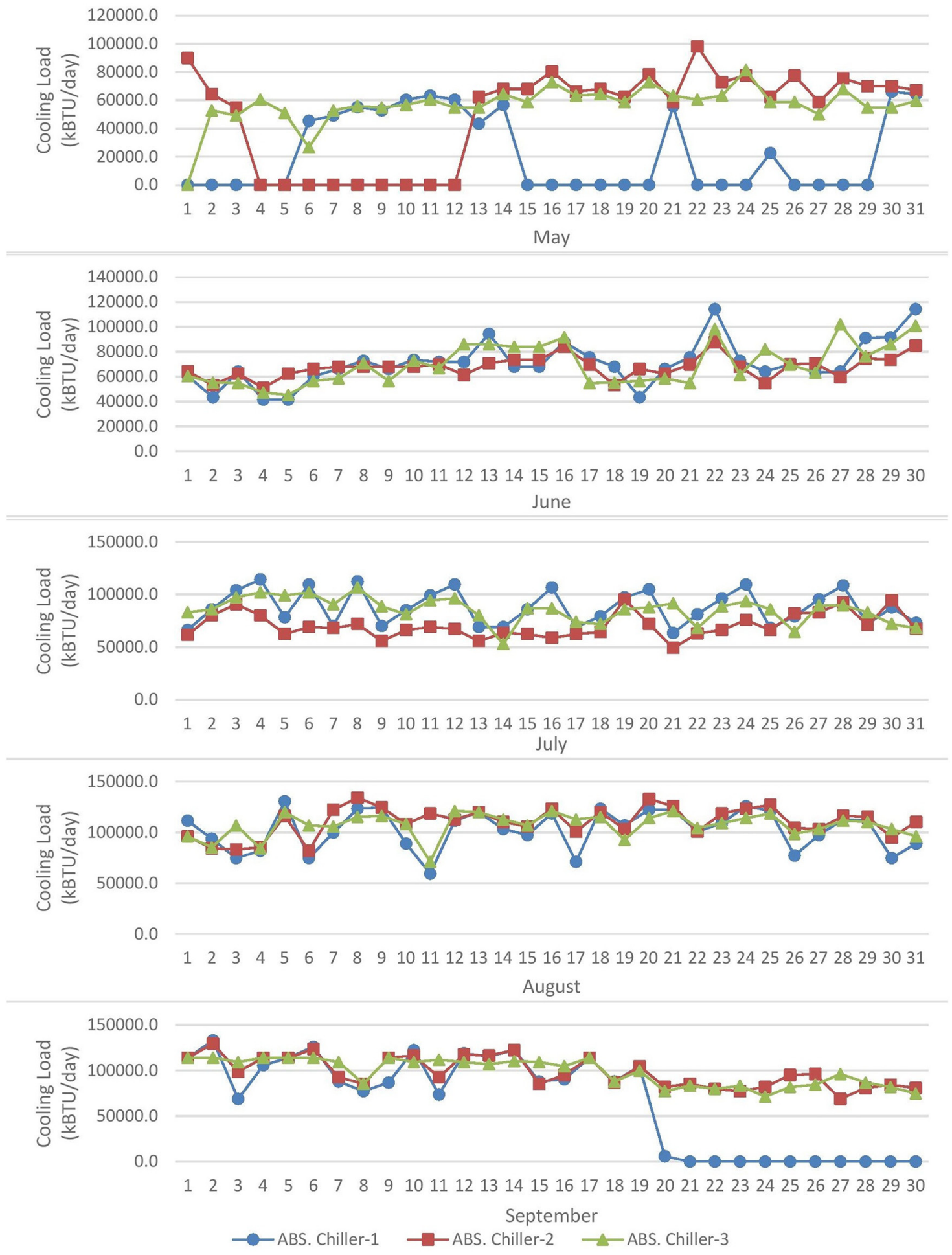

Fig. 4. Absorption chillers cooling load in May-September.

The architectural plan of Hospital building and the equipment by the existing system of central the mechanical room were modeled with all heating and cooling equipment and then, the amount of cooling load produced monthly by each chiller were evaluated.

The method for calculating thermal and refrigeration load in eQuest software is presented DOE-2 [29]. Observed heat in the building to calculate the cooling load includes the following heat sources:

- Heat transfer (which includes the displacement of energy from walls, ceilings, windows, taking into account the effect of thermal storage of the walls and ceilings on the displacement of energy, doors, etc.)

- Heat produced by the sun's radiation. 

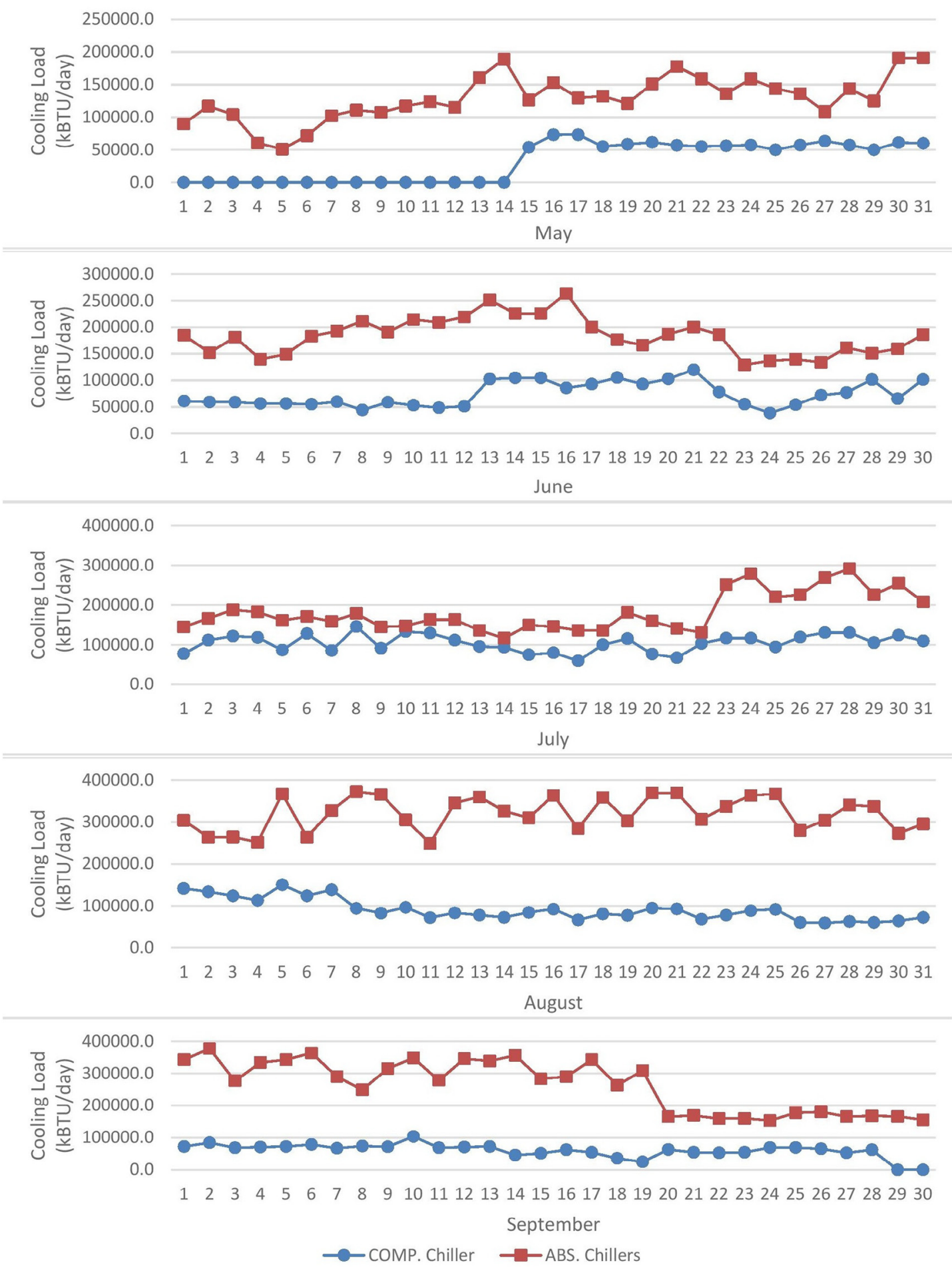

Fig. 5. Cooling rate for vapor compression and absorption chillers in May-September.

- Heat produced by the lighting system

- Heat produced by internal equipment

- Heat produced by the activity of individuals [30].

Also, in order to calculate the cooling load provided by chillers at partial load times, the ASHRAE 90.1 standard was used [31].
Equation (3) represents the cooling load produced by chillers at partial load times:

$$
Q_{\text {available }}=C A P-F T \times Q_{\text {rated }}
$$

For air cooled chillers

$$
\begin{aligned}
C A P- & F T=a+b \times T_{\mathrm{chws}}+c \times T_{\mathrm{chws}}{ }^{2}+d \\
& \times T_{\mathrm{odb}}+e \times T_{\mathrm{odb}}{ }^{2}+f \times T_{\mathrm{chws}} \times T_{\mathrm{odb}}
\end{aligned}
$$




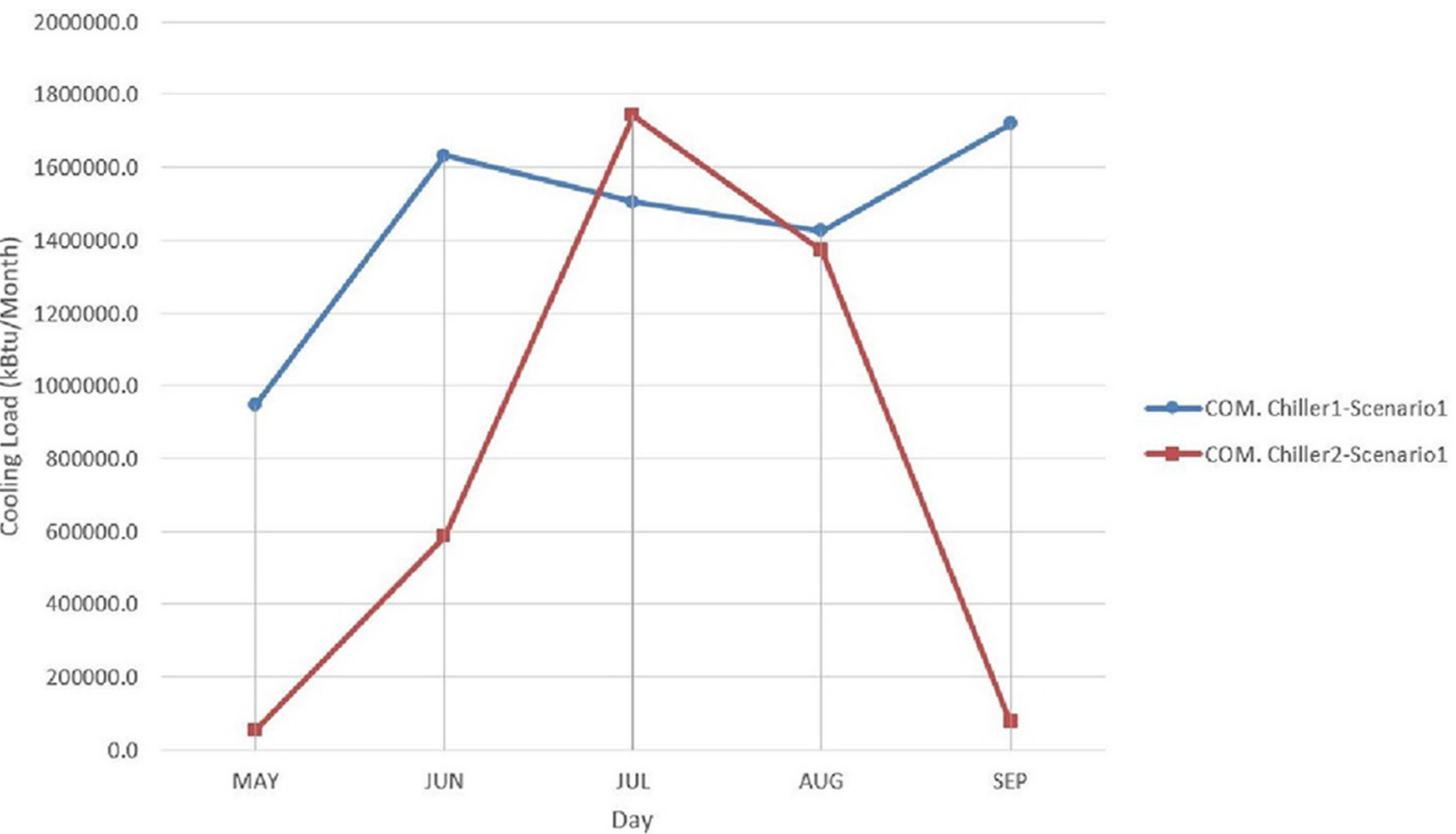

Fig. 6. The amount of cooling load provided by screw vapor compression chillers (scenario 1).

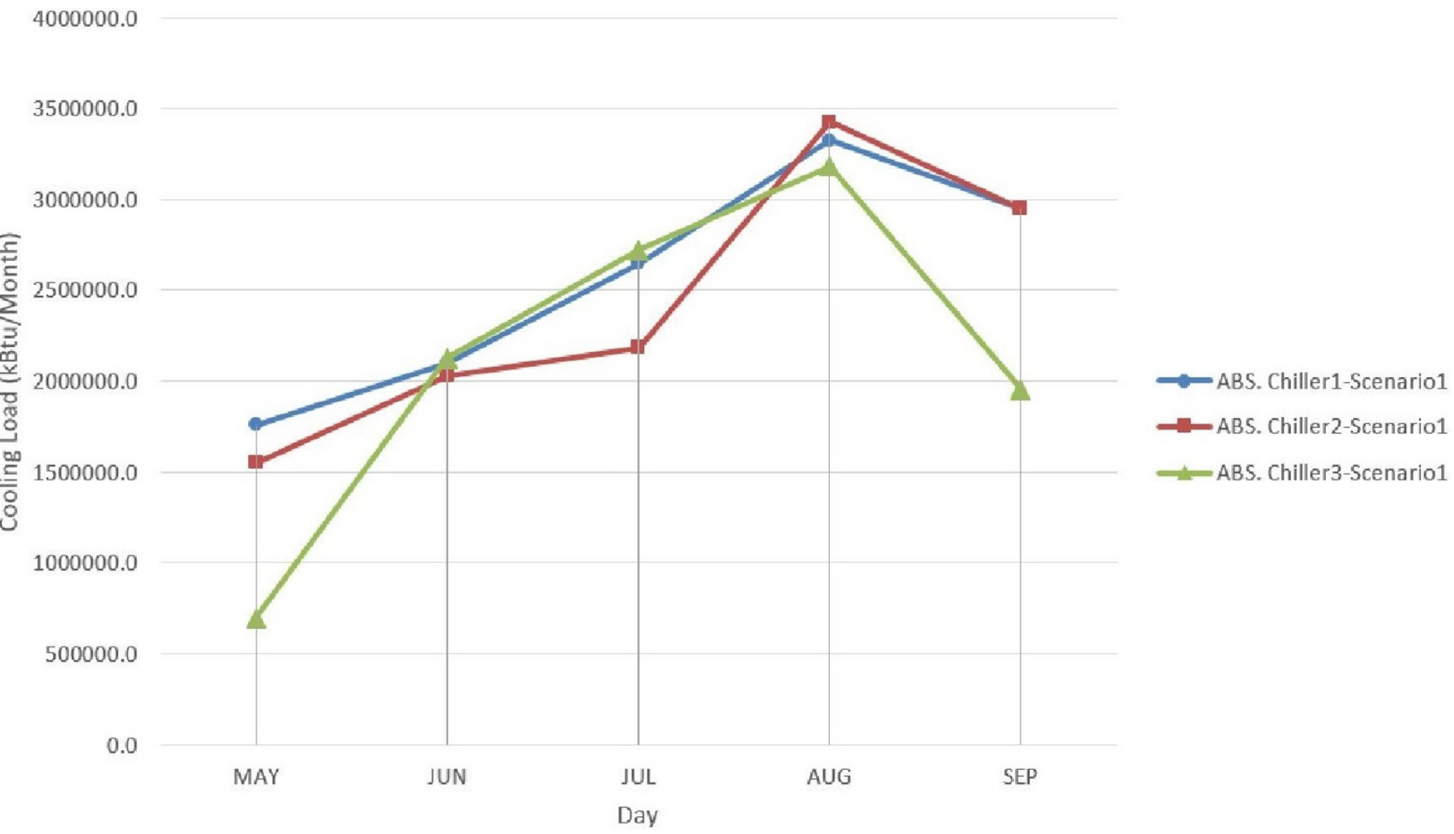

Fig. 7. The amount of cooling load provided by absorption chillers (scenario 1).

For water cooled chillers

$$
\begin{aligned}
C C A P-F T= & a+b \times T_{\mathrm{chws}}+c \times T_{\mathrm{chws}}^{2}+d \times T_{\mathrm{cws}} \\
& +e \times T_{\mathrm{cws}}^{2}+f \times T_{\mathrm{chws}} \times T_{\mathrm{cws}}
\end{aligned}
$$

The values a, b, c, d, e, f for single-effect absorption chillers and screw-air-cooled-chillers are presented in Table 3 .
The minimum and maximum range of $\mathrm{T}_{\text {chws }}:\left(\mathrm{min}=40^{\circ} \mathrm{F}\right.$, $\left.\max =54^{\circ} \mathrm{F}\right)[30]$

The minimum and maximum range of $\mathrm{T}_{\mathrm{cws}}:\left(\mathrm{min}=60^{\circ} \mathrm{F}\right.$, $\left.\max =85^{\circ} \mathrm{F}\right)[30]$

The minimum and maximum range of $\mathrm{T}_{\mathrm{odb}}:\left(\mathrm{min}=40^{\circ} \mathrm{F}\right.$, $\left.\max =115^{\circ} \mathrm{F}\right)[30]$

The amount of cooling energy provided by Vapor compression chillers and absorption chillers in 2nd Scenario is shown in Figures 8 and 9. 
As presented in Figures 8 and 9, the amount of energy supplied by the no. 2 vapor compression chiller, compared to the vapor compression chiller no. 1, is lower in all months. Also the amount of cooling load of three absorption chillers is in uniform ratio.

As the curves present, electricity consumption in July, August and September were modest, but gas consumption in August was the highest (Tab. 4).

\subsection{Validation of modeling results}

In order to validate the eQuest model results, the total cooling load provided by each of the five Vapor compression and absorption chillers in scenario 1 and eQuest model are compared in Table 5. The low amount of cooling load disruption over a total of five months between experimental data (scenario 1) and eQuest software model (scenario 1) represents the accuracy of the software model.

Table 3. Part load coefficient for air-cooled screw chillers [31].

\begin{tabular}{lll}
\hline Parameter & $\begin{array}{l}\text { Air cooled screw } \\
\text { chiller }\end{array}$ & $\begin{array}{l}\text { Single effect absorption } \\
\text { chiller }\end{array}$ \\
\hline $\mathrm{a}$ & -0.0946 & 0.72341 \\
$\mathrm{~b}$ & 0.03834 & 0.07901 \\
$\mathrm{c}$ & $-9 \mathrm{E}-05$ & 0.0009 \\
$\mathrm{~d}$ & 0.00378 & -0.0253 \\
$\mathrm{e}$ & $-1 \mathrm{E}-05$ & -0.0005 \\
$\mathrm{f}$ & -0.0015 & -0.0028 \\
\hline
\end{tabular}

\subsection{Scenario 3}

Variable flow water system considering a variable speed drive (VSD) for circulation pumps with optimized chiller sequencing to evaluate the energy consumption:

As mentioned previously variable water flow system and use of variable speed drive is one of the methods that is used for energy optimization of chiller plants. In order to investigate the effect of variable water flow system on energy consumption of hybrid air-cooled d screw vapor compressor and single effect absorption chillers for heart hospital mechanical room, variable speed drive is considered for all circulation pumps during optimal sequence of operation and time of partial load of chillers. The effect of this optimization and the comparison with scenarios 1 and 2 is presented in Figures 10-12.

\section{Conclusion}

The difference between the cooling loads provided by each of the five vapor compression and absorption chillers in scenarios 1 and 2 is high. One of the reasons for this is that the vapor compression chiller no. 2 is off during the month, which resulted in a share of cooling load being provided by other chillers.

In scenario 2, the required cooling load in a building is provided by all chillers using part load capacity control method. Regarding the validation and the acceptable difference in the load bearing capacity provided by absorption and Vapor compression chillers during the five months as previously mentioned, the possibility to compare the costs of natural gas and electricity is provided.

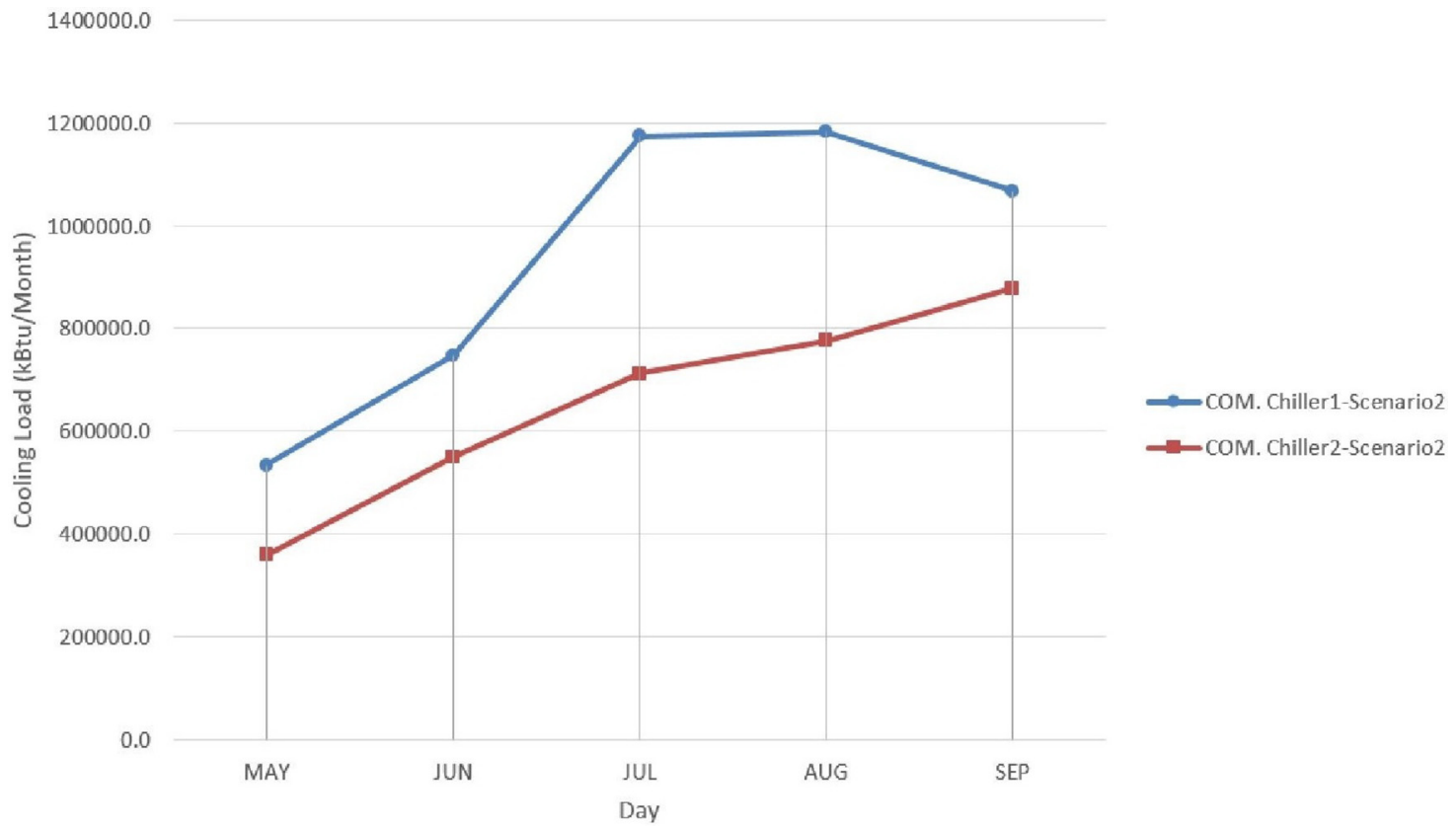

Fig. 8. Cooling loads of Vapor compression chillers in scenario 2. 


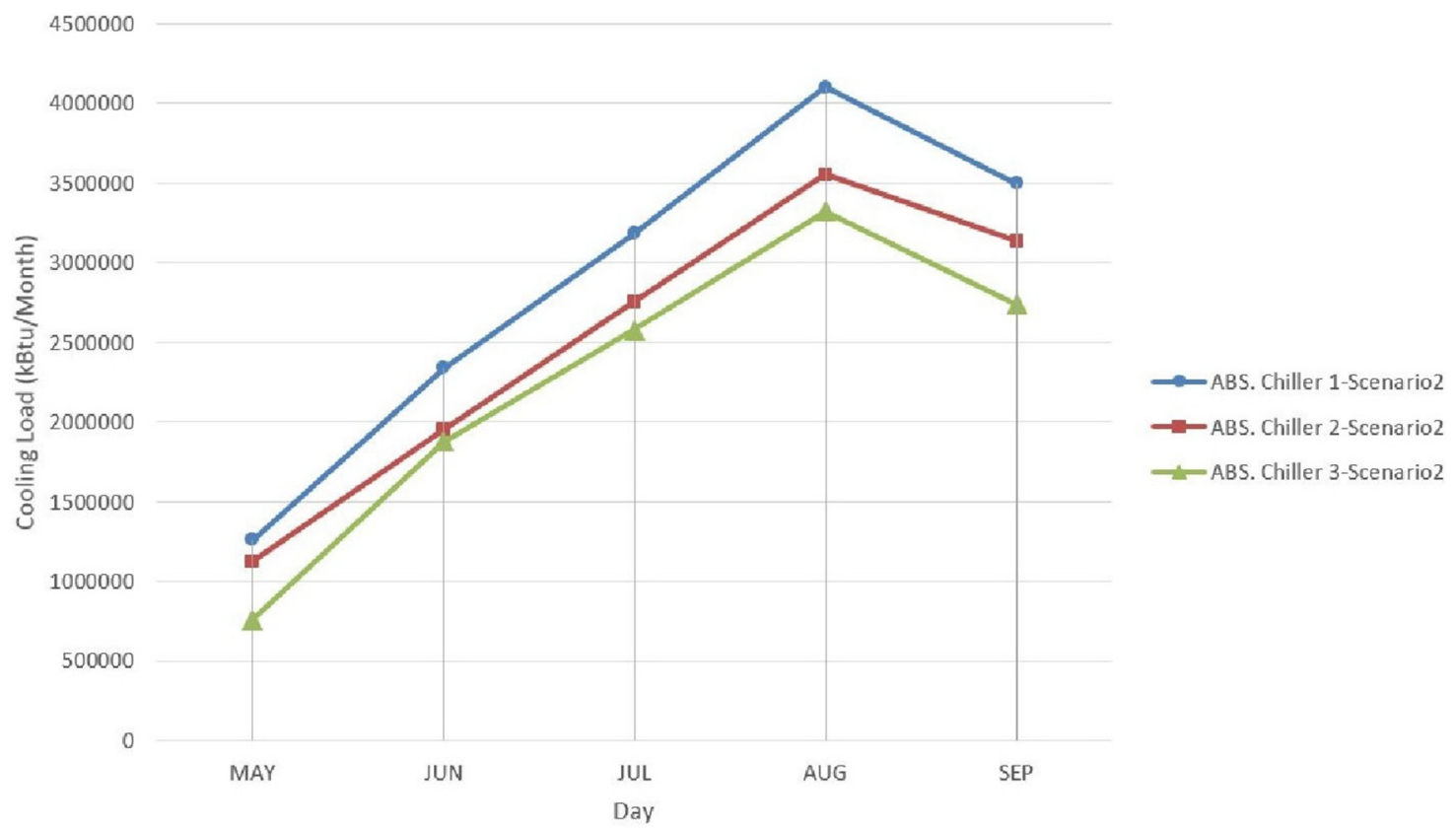

Fig. 9. Absorption chillers cooling load in scenario 2 .

Table 4. Percentage of energy saving in scenario 2 in comparison with scenario 1 for electric and natural gas consumption during investigated five month.

\begin{tabular}{lcc}
\hline & Electrical Energy $(\%)$ & Natural gas $(\%)$ \\
\hline May & 30.10 & 6.33 \\
June & 56.40 & 18.70 \\
July & 58.60 & 7.30 \\
August & 37.30 & 8.60 \\
September & 8.00 & 1.70 \\
For 5 months & 42.90 & 11.40 \\
\hline
\end{tabular}

Table 5. Comparison of total load capacity between scenario 1 and scenario 2 .

\begin{tabular}{llll}
\hline Measurement & Data & Total cooling load KBtu/month & Deviation \\
\hline For 5 Months (May-September) & Experimental data & 46674183 & $0.9 \%$ \\
\hline
\end{tabular}

In the case of optimal control of the operation of chillers (scenario 2), by controlling the share of the load between Vapor compression and absorption chillers, it is observed that the consumption of natural gas and electrical energy has decreased compared to the scenario 1.

Also, when comparing energy consumption over a fivemonth period, the amount of electricity consumption decreased $42.9 \%$ and for natural gas consumption it was $11.4 \%$. As a result, the sequence of the chiller function and the way in which they are placed in the circuit during a partial load, at a time when the combination of single effect absorption chillers and screw Vapor compression are used in one mechanical room, is in highest importance in viewpoint of energy saving. The results show that the mechanical room electrical energy saving for heart hospital application with 3 single effect absorption and two aircooled screw chillers in scenario two is $2.6 \%$ higher than the system that has been studied by Sundar Raj [20] for one centrifugal chiller and two absorption chillers for commercial buildings. In order to study the variable flow effect on scenario 2, VSD is provided for all circulation pumps in scenario three, due to this change the electrical energy consumption by pumps were reduced by $5.8 \%$. Energy saving in this study is $0.8 \%$ higher Bahnfleth [7] research that has been done for primary circuit variable flow system. 
$300,000.0$

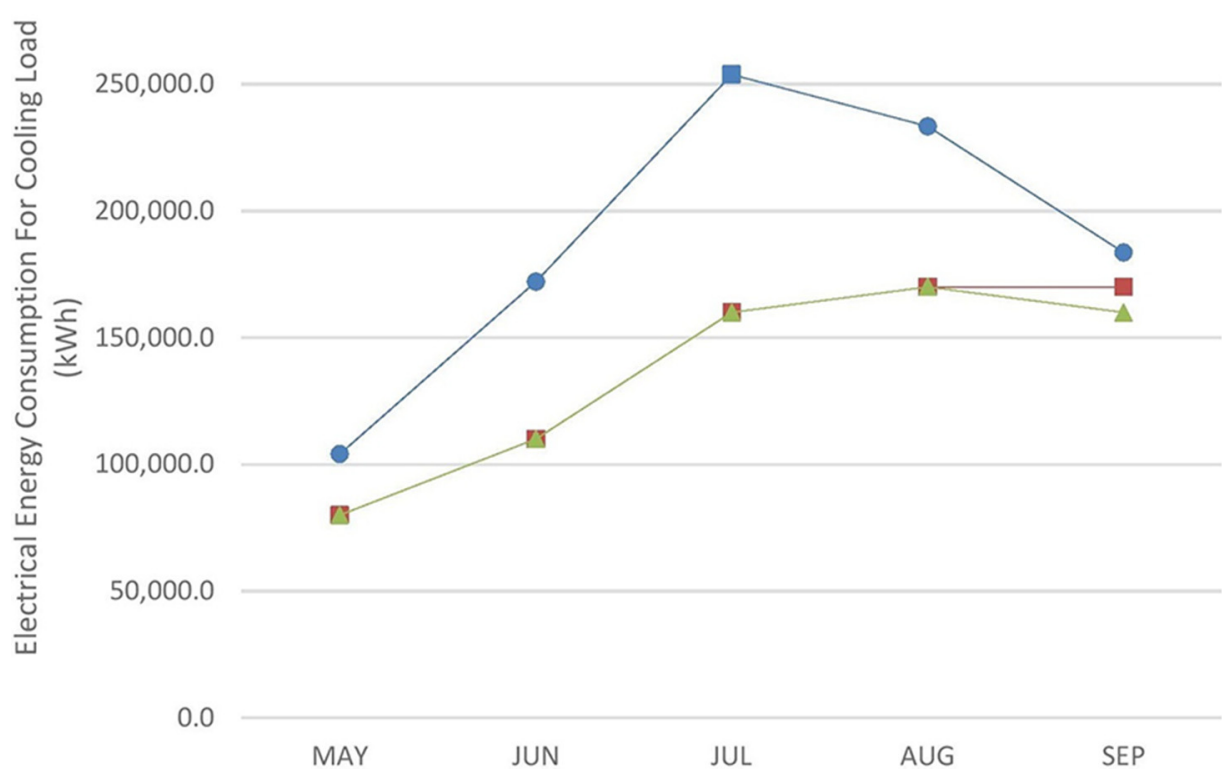

Fig. 10. Cooling load electrical energy consumption for screw chillers.

140000

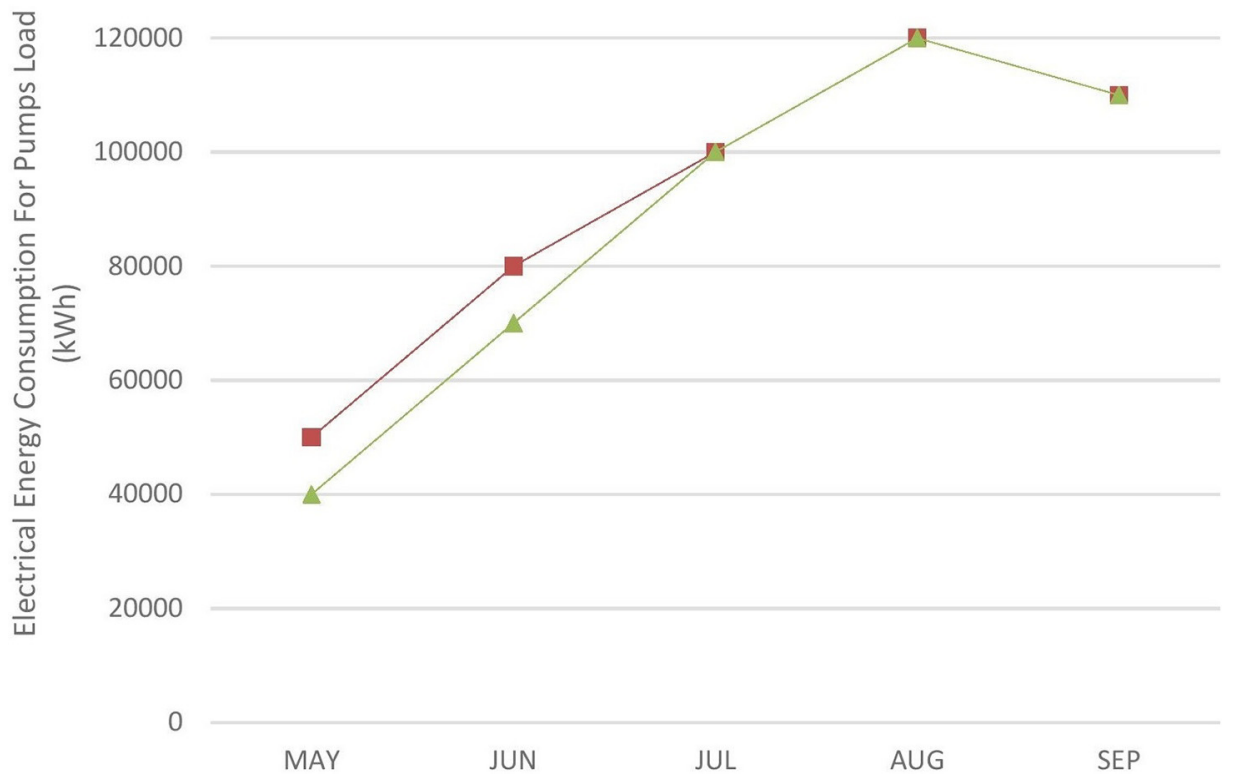

Fig. 11. Variable flow circulation pump electrical energy consumption for screw chillers. 
$700,000.0$

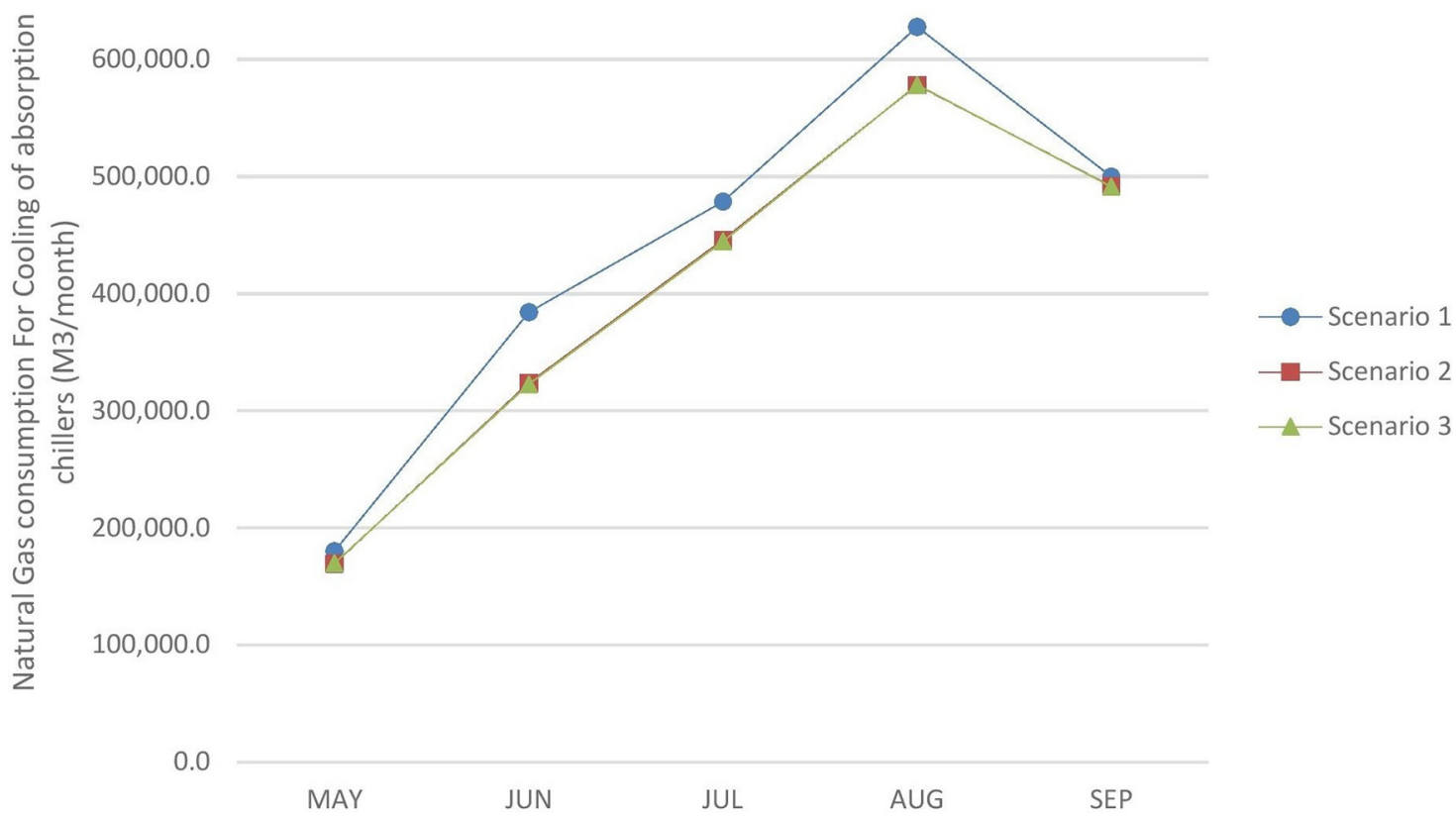

Fig. 12. Cooling load natural gas consumption for single effect absorption chillers.

\section{Nomenclature}

\section{Symbols}

$\begin{array}{ll}\text { a } & \text { Part load coefficent } \\ \text { b } & \text { Part load coefficent } \\ \text { c } & \text { Part load coefficent } \\ \text { CAP-FT } & \text { Cooling capacity adjustment factor } \\ \text { CL } & \text { Cooling capacity } \\ \text { d } & \text { Part load coefficent } \\ \text { e } & \text { Part load coefficent } \\ \text { f } & \text { Part load coefficent } \\ \text { GPM } & \text { Gallon per minut } \\ \text { I } & \text { Electrical current } \\ \text { P } & \text { Electrical power } \\ \text { Q } & \text { Cooling capacity } \\ \text { t } & \text { Time } \\ \text { T } & \text { Temperature } \\ \dot{\mathrm{v}} & \text { Water flow (gpm) } \\ \text { V } & \text { Voltage } \\ W & \text { Weighting factor } \\ \gamma & \text { Weighing factor } \\ \varphi & \text { Electrical power coefficient }\end{array}$

Subscript

chws Chilled water supply

cws Cooling water supply

$i \quad$ Time range

$o d b \quad$ Outdoor dry bulb temperature

\section{References}

[1] C.J. Renedo, A. Ortiz, M. Mañana, D. Silió, S. Pérez, Study of different cogeneration alternatives for a Spanish hospital Center, Energy and Buildings 38, 484-490 (2006)

[2] N. Thinate, Wongkot Wongsapai, Energy performance study in Thailand hospital Building, Energy Procedia 141, 251-225 (2017)

[3] C. Shen, K. ZhaoJian Ge, Q. Zhou, Analysis of building energy consumption in a hospital in the hot summer and cold winter area, Energy Procedia 158, 3735-3740 (2019)

[4] P. Rajagopalan, H. Elkadi, Energy performance of mediumsized healthcare buildings in Victoria, Australia - a case study, Journal of Healthcare Engineering. Victoria 5, 247-260 (2014)

[5] M. Schwedler, A. Yates, Applications engineering manual. Multiple chiller- system design and control, Trane, 2011

[6] A. Beghi, L. Cecchinato, G. Cosi, M. Rampazzo, A PSObased algorithm for optimal multiple chiller systems operation, Applied Thermal Engineering 32, 31-40 (2012)

[7] W.P. Bahnfleth, E.B. Peyer, Energy use and economic compartion of chilled water pumping system alternatives, Ashrae Trans Journal 112, 198-208 (2006)

[8] L. Schibuola, M. Scarpa, C. Tambani, Variable speed drive (VSD) technology applied to HVAC systems for energy saving: an experimental investigation, Energy Procedia 148, 806-813 (2018)

[9] ASHRAE handbook: HVAC Systems and Equipment, 2016 edition, ASHRAE, USA

[10] T. Hartman, All variable speed chiller plant, J Ashrae 43, 43-52 (2011)

[11] ABB: Guide to variable speed drives, technical guide no 4. (2016) 
[12] Ministry of health and medical Education, Safe Hospital Design and Planning Standard, 1th edn., Pendar Nik, Iran, 2012

[13] ASHRAE handbook: Application Handbook, American Society of Heating, Refrigerating and Air-Conditioning Engineers, ASHRAE, USA, 2015 edition

[14] Design cost data: DCD Sq. Ft. Cost Analysis New Hospital. Retrieved from: https://www.dcd.com (available in Jan. 2020)

[15] EIA, Energy Information Administration, Retrieved from: https://www.eia.gov/ (available in Dec. 2019)

[16] IEA, International Energy Agency, Online Energy Statistics, Energy Balances; Retrieved from: http://www.iea.org/stats (available in Nov. 2019)

[17] L. Perez-Lombard, J. Ortiz, I.R. Maestre, The map of energy flow in HVAC systems, Applied Energy 88, 5020-5031 (2011)

[18] R. Saidur, M. Hasanuzzaman, T.M.I. Mahlia, N.A. Rahim, H.A. Mohammedd, Chillers, energy consumption, energy savings and emission analysis in an institutional buildings, Energy 36, 5233-5238 (2011)

[19] Lal Jayamaha: energy efficient building systems, McGraw Hill, New York, 2008

[20] S.R. Thangavelu, A. Myat, A. Khambadkone, Energy optimization methodology of multi-chiller plant in commercial buildings, Energy 123, 64-76 (2017)

[21] C.J. Xing, P. Ren, J. Ling, Analysis of energy efficiency retrofit scheme for hotel buildings using EQuest software: a case study from Tianjin, Energy and Buildings 87, 14-24 (2015)

[22] A.H. Neto, F.A. Sanzovo Fiorelli, Comparison between detailed model simulation and artificial neural network for forecasting building energy consumption, Energy and Buildings 40, 2169-2176 (2008)

[23] M.-T. Kea, C.-H. Yeha, J.-T. Jian, Analysis of building energy consumption parameters and energy savings measurement and verification by applying EQUEST software, Energy and Buildings 61, 100-107 (2013)

[24] H. Sozer, Improving energy efficiency through the design of the building envelope, Building and Environment 45, 2581-2593 (2010)

[25] G. Kim, H.S. Lim, T.S. Lim, L. Schaefer, J.T. Kim, Comparative advantage of an exterior shading device in thermal performance for residential buildings, Energy and Buildings 46, 105-111 (2012)

[26] BITZER Company, Capacity control of screw compressors, Engineering document Retrieved from: https://www.bitzer. de/ir/en/documentation (Dec. 2017)

[27] Ronald Boghosian: HVAC calculation, 2th edition, Yazda, Iran, 2019

[28] ASHRAE handbook: System and equipment Handbook, American Society of Heating, Refrigerating and AirConditioning Engineers, ASHRAE, USA, 2016 edition

[29] ASHRAE handbook: Fundamental Handbook. American Society of Heating, Refrigerating and Air-Conditioning Engineers, ASHRAE, USA, 2013 edition

[30] Energy and Environment Division Building Energy Simulation Group Lawrence Berkeley Laboratory: DOE-2 Engineering Manual, University of California Berkeley, 1982

[31] S. Goel, M. Rosenberg, C. Eley, ANSI/ASHRAE/IES Standard 90.1 Performance Rating Method Reference Manual, NTIS, USA, 2017 edition

Cite this article as: R. Boghosian, M. Mafi, M.H. Panjeshahi, A. Ataei, Variable flow and optimization of chiller loading effect on energy saving for screw vapor compression-single effect absorption hybrid chiller plant in hospital mechanical room - case study: Tehran heart hospital, Mechanics \& Industry 22, 9 (2021) 